\title{
Sofrimento no Trabalho e a Atuação de Psicólogos em Diferentes Contextos Laborais
}

\author{
Suffering at Work and the Role of Psychologists \\ in Different Work Contexts
}

\section{El Sufrimiento en el Trabajo y el Papel de los Psicólogos en Diferentes Contextos Laborales}

\author{
Luciana Mourão ${ }^{1}$ \\ ${ }^{1}$ Universidade Salgado de Oliveira, RJ, Brasil.
}

No final do século XX, as reflexões sobre a precarização do trabalho já vinham sendo discutidas a partir de uma perspectiva que não era apenas nacional, mas que contava também com elementos da reestruturação produtiva, da integração mundial dos mercados financeiros e da internacionalização e abertura das economias (Gomez \& Thedim-Costa, 1999). Na esteira desses processos, a terceirização passou a ser efetivada como uma prática cada vez mais frequente. No Brasil, estudos das últimas três décadas apontam para a degradação do trabalho advinda da terceirização, observada pelo desrespeito aos direitos trabalhistas, pelas más condições de trabalho, pelos baixos salários e pela piora das condições de saúde dos trabalhadores (Druck, 2016).

Somado a esse cenário macroeconômico e político global, tivemos, no caso brasileiro, a Lei da Reforma Trabalhista que entrou em vigor em 11 de novembro de 2017 (Lei no 13.467), que alterou substancialmente a Consolidação das Leis do Trabalho (CLT). As consequências da nova legislação para os trabalhadores têm sido expressivas, com aumento do subemprego, fragilização dos vínculos de trabalho e aumento da insegurança (Filgueiras, 2019). Se, por um lado, a Reforma Trabalhista não cumpriu as promessas de redução do desemprego e de aumento da formalização, que embasaram sua implementação (Filgueiras, 2019), por outro, seus impactos na remuneração e nas condições de trabalho são visíveis, assentados em um processo de flexibilização da jornada, que tende a prejudicar tanto o acesso aos benefícios da seguridade social quanto suas fontes de financiamento - com a introdução de formas mais instáveis e precárias de contratação (Krein \& Oliveira, 2019).

Não bastassem todos os desafios inerentes ao contexto laboral contemporâneo, a pandemia da Covid-19 imprimiu uma nova dinâmica à economia mundial. O necessário isolamento social imposto pela doença teve efeitos severos para pessoas que vivem na informalidade, além de demissões em massa em âmbito nacional e mundial, afetando, sobretudo, aqueles que vivem do trabalho precário, como os terceirizados (Costa, 2020).

Todo esse cenário acarreta impactos na saúde física e mental do trabalhador e cria desafios para os profissionais que estudam tal temática ou que com ela atuam. Nessa complexa conjuntura, a atuação dos psicólogos requer o desenvolvimento de reflexões, de contrapontos, de estratégias sobre novos rumos e de resistência no campo profissional e científico. É nesse diapasão que a revista Psicologia: Ciência e Profissão apresenta este número temático com artigos voltados à saúde mental no trabalho e à atuação de psicólogos em diferentes contextos laborais.

Os doze artigos que compõem este número foram organizados em dois eixos centrais. O primeiro é sobre a Prática Profissional em Psicologia, com análises tanto sobre a atuação quanto sobre a formação de psicólogas e psicólogos no país. O segundo eixo versa sobre o Sofrimento Psíquico no Trabalho em diferentes contextos laborais, como um dos temas 
centrais sobre o qual as psicólogas e os psicólogos se debruçam. Como transição entre os dois eixos, há um artigo que versa simultaneamente sobre a prática profissional em Psicologia e o sofrimento psíquico nos trabalhadores, a partir da vertente da psicodinâmica do trabalho e, mais especificamente, da escuta na clínica do trabalho.

Essas reflexões sobre a prática profissional de psicólogas e psicólogos com um recorte para a saúde pública e a assistência social é consonante com o crescimento da Psicologia nesses campos de atuação. A inserção do psicólogo no setor público de saúde no Brasil ocorreu em um momento em que o modelo médico privatista-assistencial estava em decadência e o modelo de grupos multiprofissionais, em ascensão. Ademais, o mercado de atendimento psicológico privado estava em redução em função de uma crise econômica e havia um ambiente de críticas à falta de significado social da psicologia clínica tradicional, o que instigou o surgimento de outras práticas profissionais na Psicologia mais voltadas para o contexto social (Carvalho \& Yamamoto, 2002).

Nesse sentido, os artigos referentes ao eixo da Prática Profissional em Psicologia se voltam para a saúde pública, o Sistema Único de Saúde (SUS), abordando a atuação e a formação dos psicólogos para atuarem na Atenção à Saúde Básica, em Unidades de Ponto Atendimento (UPA), considerando também o modelo de equipes multiprofissionais do SUS. Em uma linha semelhante, também são feitas abordagens sobre o trabalho de psicólogas e psicólogos no Sistema Único de Assistência Social (Suas), bem como reflexões sobre estágio curricular nas redes de assistência social.

Abrindo este primeiro eixo, temos o artigo "Práticas de psicólogos na Estratégia Saúde da Família: poder simbólico e autonomia profissional", de autoria de Léo Barbosa Nepomuceno, Maria Lúcia Magalhães Bosi, Magda Dimenstein e Ricardo José Soares Pontes. Esse estudo qualitativo de pesquisa social em saúde discute a inserção de psicólogos nos serviços de atenção primária do SUS, através da Estratégia Saúde da Família, debatendo o papel de agente problematizador e mediador nas relações interprofissionais. Nele são discutidas, com pertinência, as tensões concernentes às lutas por autonomia das psicólogas e psicólogos, as especificidades de sua atuação nesse contexto, além da necessidade de elaborar posicionamentos que façam contraponto ao modelo biomédico.
No contexto do SUS, há também o estudo apresentado por Isabel Sampaio dos Santos Ferreira e Cecília Teixeira Soares, intitulado "Residência Multiprofissional em Saúde e formação de psicólogos para o SUS", cujo enfoque se assenta sobre a formação para a atuação nesse contexto. $\mathrm{O}$ efeito das vivências da residência para a formação profissional ganha centralidade nesse artigo, em paralelo à discussão da importância do trabalho multiprofissional para garantir atenção integral em saúde. Assim, os autores conseguem debater a prática profissional em Psicologia ao mesmo tempo em que apontam as frustrações dos residentes ao lidar com o atual contexto de sucateamento do SUS. Nesse processo, vai ficando evidente para o leitor que a ancoragem na área clínica - ainda existente da graduação em Psicologia - gera lacunas na formação das psicólogas e psicólogos que pretendem atuar no campo da saúde pública, permitindo uma conclusão acerca da necessidade de maior inclusão, nas grades curriculares, das temáticas de grupo, saúde e gênero.

De forma similar, o artigo "Considerações sobre a ampliação da intensão da psicanálise numa Unidade de Pronto Atendimento" também se situa no eixo da Prática Profissional em Psicologia e no contexto da saúde pública. Os autores Maico Fernando Costa e Abílio da Costa-Rosa compartilham a experiência da ação-reflexão do psicólogo nesse campo específico da Atenção em Saúde. O dispositivo Clínica da Urgência na proposição teórico-clínica e ético-política descrita pelos autores almeja a escuta dos sujeitos em sofrimento, configurando uma discussão em que a Psicanálise foi o principal instrumento de trabalho. Assim, a práxis de escuta das psicólogas e psicólogos é discutida, com contribuições de textos freudianos e lacanianos, com um olhar para os sujeitos em sofrimento.

Também na linha da saúde pública e da discussão sobre a formação em Psicologia, Taise Signorini, Fátima Ferretti e Maria Elisabeth Kleba da Silva apresentam um estudo sobre as práticas realizadas com foco na saúde pública durante o processo de graduação em um curso de Psicologia baseado em análise documental e entrevistas. Assim, no artigo "Práticas em Psicologia na saúde pública: aproximando cenários e contextos", as autoras discutem que as vivências realizadas pelos estudantes ao longo da formação em Psicologia são escassas, já que a maioria das práticas na saúde pública é realizada nos estágios 
obrigatórios. Assim como no primeiro artigo deste eixo, as autoras sinalizam para a demanda por uma articulação entre o ensino e o serviço, com práticas mais integralizadas e articuladas.

O eixo da Prática Profissional em Psicologia também contempla estudos voltados para a atuação no campo da Assistência Social. O artigo "Trabalhadoras(es) do SUAS: quem são as(os) psicólogas(os) da Proteção Social Básica (PSB)", de Roberta Fin Motta, Catheline Rubim Brandolt e Adolfo Pizzinato, apresenta o perfil das(os) psicólogas(os) vinculadas(os) ao Suas com um olhar para a inserção nos Centro de Referência de Assistência Social (Cras). Os autores denunciam condições adversas da formação e das relações de trabalho, e discutem que o campo - por ser ainda recente - carece de construções epistemológicas próprias para sua efetivação.

Os desafios da Assistência Social são alvo igualmente do artigo "Reflexões sobre práticas e cotidiano institucional na rede de proteção à mulher", de autoria de Janine Conceição de Araújo e Silva, Letícia Lívia de Araújo Santos, Victor Hugo Belarmino e Magda Dimenstein. O enfoque, aqui, volta-se mais uma vez para a formação em Psicologia, sendo debatido um relato de experiência elaborado a partir de um estágio curricular em Psicologia na Rede de Proteção à Mulher. Sob o referencial teórico da Análise Institucional, os autores revelam uma atuação profissional ainda marcada por estereótipos de gênero, práticas prescritivas e posturas moralistas e discutem a fragilidade do funcionamento em rede, a desarticulação dos serviços e pouca fluidez do fluxo assistencial às mulheres vítimas de violência.

Fechando o conjunto de artigos no eixo da Prática Profissional em Psicologia, o estudo conduzido por Dhayanne de Sousa Silva, Heila Magali da Silva Veiga e Pedro Afonso Cortez aborda alternativas para a inserção profissional das psicólogas e psicólogos em um contexto de precarização das relações de trabalho e emprego. Assim, o artigo "Motivações, desafios e dificuldades vivenciados por psicólogos empreendedores" discute motivações, desafios e dificuldades para empreender em Psicologia. As barreiras para proposição do próprio negócio, as relações com agentes de interesse, as estratégias empregadas para manter o negócio e as dificuldades para empreender configuram os principais desafios ao empreendedorismo entre psicólogos.

Na transição entre o eixo da Prática Profissional em Psicologia e o eixo do Sofrimento Psíquico no
Trabalho, está um artigo que contempla simultaneamente essas duas temáticas: "Escuta do sofrimento no trabalho: contribuições da psicanálise para o exercício profissional". Esse artigo, de autoria de Victoria Ayelen Gomez, Daniela Scheinkman Chatelard e Tereza Cristina Cavalcanti Ferreira de Araujo, parte da Psicodinâmica do Trabalho, sob a égide da escuta da palavra na Clínica do Trabalho, e fundamenta-se na lógica da singularidade de cada sujeito e nos significantes que marcam a história de cada trabalhador. Mas a adoção desse racional não polariza a discussão em torno do indivíduo, uma vez que as autoras discutem também os determinantes e condicionantes sociais e organizacionais associados ao sofrimento no trabalho.

A saúde do trabalhador e o sofrimento psíquico no trabalho têm sido temas cada vez mais presentes em pesquisas na área de Psicologia. Essa discussão vai desde pesquisas em contextos diversificados como as que compõem este número temático da revista Psicologia: Ciência e Profissão - até estudos mais amplos como aqueles relativos ao Centro de Referência em Saúde do Trabalhador (Cerest), que é considerado polo irradiador das políticas em saúde do trabalhador no Brasil (Keppler \& Yamamoto, 2016). Neste número temático, será apresentada uma revisão sistemática sobre o sofrimento psíquico no trabalho e, também, estudos com categorias ocupacionais específicas, como os agentes de segurança penitenciário, os profissionais que atuam em abrigos institucionais e os trabalhadores rurais assentados.

Assim, abrindo o conjunto dos artigos do eixo temático sobre Sofrimento no Trabalho, Ana Verônica de Alencar e Edil Ferreira da Silva apresentam o artigo "Revisão sistemática sobre Trabalho, Racismo e Sofrimento Psíquico no contexto brasileiro". Tendo como foco o sofrimento psíquico para o trabalhador negro, a pesquisa foi realizada a partir de uma busca em diferentes bases de dados. $\mathrm{O}$ estudo aponta a presença de documentos advindos de diferentes áreas como Sociologia, Política, Educação, Psicologia, Serviço Social, Literatura e Linguística, e indica uma escassez de artigos sobre racismo e sofrimento psíquico nas relações intersubjetivas de trabalho. Os estudos revisados apresentam importantes denúncias relativas às dificuldades de inserir o negro no mercado de trabalho formal, aos padrões distintos de rendimentos entre negros e brancos e às barreiras de ascensão social do trabalhador negro. As demandas psíquicas que circundam as relações de trabalho do 
indivíduo negro são discutidas e assinalam a necessidade de aprofundamento desse debate.

Nesse eixo do sofrimento psíquico no trabalho, além da revisão de literatura que abre as discussões, há três artigos voltados para diferentes contextos laborais. O primeiro deles é "Estresse e Estratégias de Enfrentamento em Profissionais de Abrigos Institucionais", de autoria de Rosângela Maria Negri Ferrão Pagnota e Helena Bazanelli Prebianchi. O estudo analisa os níveis de estresse percebido e as estratégias de coping dos profissionais de contato direto e indireto com abrigados, em quatro abrigos institucionais de assistência a crianças e adolescentes. As autoras identificaram que os níveis de estresse percebido foram maiores nos participantes de abrigos filantrópicos de contato direto com abrigados e que o coping focalizado no problema é a estratégia mais frequentemente usada por esses trabalhadores. Sinaliza-se para a necessidade de avaliação da saúde dos profissionais de abrigos como passo inicial para o desenvolvimento de ações e políticas dirigidas a esses trabalhadores.

Outro contexto laboral difícil é o dos presídios, que é contemplado no estudo apresentado por Sara Rodrigues de Jesus, Andreia Monteiro Felippe e Yury Vasconcellos da Silva, intitulado "Vulnerabilidade ao estresse em agentes de segurança penitenciários". A pesquisa de delineamento comparativo e correlacional revela que a pressão por trabalho em longos turnos, o ambiente tenso e a constante exposição ao perigo são fatores que aumentam a vulnerabilidade ao estresse nos trabalhadores que atuam em unidades prisionais. Os trabalhadores pesquisados mantêm contato direto com os presos e seu escore médio de vulnerabilidade ao estresse classificou-se no nível superior da medida, com os agentes penitenciários solteiros apresentando médias estatisticamente superiores aos demais. Da mesma forma, quem já foi afastado por motivos de doenças apresenta níveis mais elevados de vulnerabilidade ao estresse no fator relativo à infraestrutura e à rotina organizacional. Os autores ressaltam a importância de políticas públicas para combater o fenômeno.

Por fim, temos o artigo "Sofrimento social de trabalhadores rurais assentados na contracorrente do agronegócio, na Bacia do Juruena-MT", de Bianca Vasquez Pistório de Castro, Luís Henrique da Costa Leão e Marta Gislene Pignatti, que aborda um contexto em que o sofrimento dos trabalhadores tem múltiplas fontes. Nesse estudo, são compartilhadas reflexões acerca da ocupação e da luta pela terra, com diferentes consequentes. Por um lado, são geradas disputas advindas da configuração econômica e repercussões na subjetividade dos trabalhadores; por outro, a luta pela terra gera união no grupo e o fortalece para resistir às pressões externas ao assentamento, sublinhando o papel da coletividade como um mecanismo que permite desenvolver estratégias defensivas ao sofrimento social.

Se considerarmos que a Prática Profissional em Psicologia e o Sofrimento Psíquico no Trabalho são tópicos de relevo para psicólogas e psicólogos, este número temático oferece contribuições importantes para a formação e a atuação na área. Uma diversidade de estratégias metodológicas - entrevistas, grupos focais, questionários, análise documental, análise institucional, revisão sistemática, processos de escuta para além do tradicional setting analítico - são exploradas pelos doze artigos deste número. Além disso, a contemplação de contextos laborais complexos e relevantes na saúde pública, na assistência social, no empreendedorismo, nos assentamentos rurais, nas penitenciárias, e nos abrigos institucionais - enriquece a discussão proporcionada por esta edição da revista Psicologia: Ciência e Profissão. Boa leitura!

\section{Referências}

Carvalho, D. B., \&Yamamoto, O. H. (2002). Psicologia e políticas públicas de saúde: Anotações para uma análise da experiência brasileira. Psicologia para América Latina, (0), 1-8.

Costa, S. S. (2020). The pandemic and the labor market in Brazil. Revista de Administração Pública, 54(4), 969-978. https://doi.org/10.1590/0034-761220200170x

Druck, G. (2016). A terceirização na saúde pública: Formas diversas de precarização do trabalho. Trabalho, Educação e Saúde, 14(Suppl.1), 15-43. https:// doi.org/10.1590/1981-7746-sol00023

Filgueiras, V. A. (2019). As promessas da Reforma Trabalhista: Combate ao desemprego e redução da informalidade. In J. D. Krein, R. V. Oliveira, \& V. A. Filgueiras (pp. 13-52), Reforma Trabalhista no Brasil: Promessas e realidade. Curt Nimuendajú. 
Gomez, C. M., \& Thedim-Costa, S. M. F. (1999). Precarização do trabalho e desproteção social: Desafios para a saúde coletiva. Ciência \& Saúde Coletiva, 4(2), 411-421. https://doi.org/10.1590/S1413-81231999000200015

Keppler, I. L. S., \& Yamamoto, O. H. (2016). Psicólogos nos Centros de Referência em Saúde do Trabalhador. Revista Psicologia, Organizações e Trabalho, 16(1), 48-60. https://doi.org/10.17652/rpot/2016.1.646

Krein, J. D., \& Oliveira, R. V. (2019). Os impactos da Reforma nas condições de trabalho. In J. D. Krein, R. V. Oliveira, \& V. A. Filgueiras (Orgs.), Reforma Trabalhista no Brasil: Promessas e realidade (pp. 127-154). Curt Nimuendajú.

\section{Luciana Mourão}

Professora visitante da Universidade do Estado do Rio de Janeiro e professora titular da Universidade Salgado de Oliveira, Niterói - RJ. Brasil.

E-mail: mourao.luciana@gmail.com

(1) http:// orcid.org/0000-0002-8230-3763

Como citar: Mourão, L. (2021). Sofrimento no Trabalho e a Atuação de Psicólogos em Diferentes Contextos Laborais. Psicologia: Ciência e Profissão, 41, 1-5. https://doi.org/10.1590/1982-3703003022020

How to cite: Mourão, L. (2021). Suffering at Work and the Role of Psychologists in Different Work Contexts. Psicologia: Ciência e Profissão, 41, 1-5. https://doi.org/10.1590/1982-3703003022020

Cómo citar: Mourão, L. (2021). El Sufrimiento en el Trabajo y el Papel de los Psicólogos en Diferentes Contextos Laborales. Psicologia: Ciência e Profissão, 41, 1-5. https://doi.org/10.1590/1982-3703003022020 